\title{
An Investigation of the Role of Female Entrepreneurship in the Economic Development of Saudi Arabia
}

\author{
Afrah Alrasheedi*, Ghaith Abualfalayeh ${ }^{\#}$ \\ *Email: Afraah92 [AT] hotmail.com \\ ${ }^{\#}$ Email: gogo5002 [AT] hotmail.com
}

\begin{abstract}
In the modern days, the role of female entrepreneurship has been expanded in the market and they also play their essential role in the contribution in the economic development for their respective nations. The aim of the study is to analyse and investigate the role of female entrepreneurship in the development of the economic condition in Saudi Arabia. The introduction section mainly sheds light on the research aim, objective and the research questions in order to provide the abrupt understanding of the research. The section also provides the justification for the research along with the structure of the study. In addition to this, the research methodology section provides a complete understanding of the research philosophy, approach, and design and data collection method. Additionally, in this research, the data has been collected with the help of secondary research. In the data finding section, the research provides the different types of theme in order to highlight the role of female entrepreneurship in the development of the national economic condition.
\end{abstract}

Entrepreneurship development by women's group has been one of the major realms that are adopted by various organisations all over the world. The presence of various traditional and cultural norms has restricted women from attaining entrepreneurship engagement for a successful business environment in the Saudi Arabian region. This is because the Saudi Arabian government has laid the Limited number of services that a woman can avail in the economic framework of the country. The study claims to identify the benefits and challenges that arise while reforming the existing architecture and economical background of Saudi Arabia to that of the women employment criteria in business operations. In other words, the facilitation of women to attain Entrepreneurship and self-governing business need to be attained in order to gain economic growth regarding the financial aspects of the country. The study considers several theoretical frameworks including the Krueger and Brazeal's model of entrepreneurship potential so as to investigate perceived official feasibility propensity to act and perceive desirability for women in employment. Deducing entrepreneur opportunities regarding women residing in the Saudi Arabian region has often been our challenging aspect as religious and cultural rights are post against women. However, the importance of including women in business has been observed to provide the country in attaining business growth in the Global region of operation. Similarly, the Saudi Arabian region upon having a strong oil refinery bass would also be required to make them self-independent of another business sector that is to be developed in that region. The study provides a detailed analysis through data collection from various samples in an exploratory way to reduce conclusions regarding the benefits of including women in entrepreneurship and development.

In the conclusion and recommendation section the research draft the overall summary of the research and provide the objective linking. The objective linking helps the researcher to correlate with the section of the study and where the specified objective has been met. The research future scope and limitation has been providing that in future the research scholar needs to expand the research in the form of open-ended and interview questionnaires in order to collect the individual aspects regarding the topic. The recommendation has been provided to the authority and society so that they can be able to promote the female entrepreneurship activities for the development of the national economic condition.

Keywords---- Entrepreneur, Saudi Arabia, Data collection

\section{INTRODUCTION}

\subsection{Introduction}

In the modern world, social entrepreneurship is the process of enhancing innovative solution in order to mitigate social problems. In the modern days, women are taking one step lead from the men in the market as well as in society. The fostering the development of the entrepreneurship sectors mainly leads with the help of political agendas for the empowerment of the women. Based on the Islamic laws and regulations the Saudi Arabian government have its restriction for the women job opportunities and rights in the nation. In other words, the main constraint that has been emerging with 
the female entrepreneurship for the development of the economic condition is their lifestyle and the rate of employment. This study sheds light on the role of female entrepreneurship in the development of the economic condition in the market of Saudi Arabia.

\subsection{Research Aim}

The aim of the research is to investigate the role of female entrepreneurship in the economic development of Saudi Arabia.

\subsection{Research Objectives}

- To determine the importance of entrepreneurship activities in the development of economic condition for the nation

- To evaluate the impact of female entrepreneurship in the development of the economic condition of Saudi Arabia

- To investigate the role of female entrepreneurship in the development of the economic condition of Saudi Arabia

- To assess the issues that have been faced by the female person in female entrepreneurship for the development of the economic condition in the nation

- To provide the necessary strategies in order to resolve the issues of female entrepreneurship for the development

\subsection{Research Questions}

1. What are the role and contribution of female entrepreneurship in the development of the economic condition of Saudi Arabia?

2. What are the issues faced by the individual in developing the economic conditions for the nation?

3. What are the strategies that need to be undertaken to resolve the issues that have been faced with the activities of female entrepreneurship?

\subsection{Problem statement}

The main problem that has been faced by the female entrepreneur is related to the restriction in the nation are related to their lifestyle and empowerment. In the market of Saudi Arabia, those women run their own business they are not allowed to derive their contribution to the economic growth for the nation. The other issues are related to the traditional culture of the nation and that is one of the vital factors that restrict the women to show their talents (Berger and Kuckertz, 2016). In recent days, the government of Saudi Arabia runs a program in order to enhance the female workers are entrepreneurship for the development of the national economic condition. In addition to this, the other challenges include the high rate of unemployment among the youth population between the age group of 15 to 24 and the ratio of unemployment for that age is about to $28.20 \%$ (tradingeconomics.com, 2020). The female entrepreneur is also facing issues with the lack of business opportunities and also lags in the business education program.

\subsection{Justification of the study}

In recent days, women entrepreneurship has been recognised as one of the essential contributions to the global economy. According to the statistical data, in the worldwide 104 millions of women run their business in 59 economics (tradingeconomics.com, 2020). In comparison to men entrepreneurship, women entrepreneurship still remains the minorities in recent days especially in the market of Saudi Arabia (Poggesi et al., 2016). This study is about the roles and contribution of female entrepreneurship in the development of economic condition for the nation, Saudi Arabia. The sturdy mainly sheds light on the role and the responsibility of the female entrepreneurship in the development of the economic condition and the issues that have been faced by the female entrepreneur in the development. This study also provides an adequate understanding of the strategies that need to be undertaken in order to help the female entrepreneur for the development of the economic condition in the market of Saudi Arabia. 


\subsection{Structure of Paper}

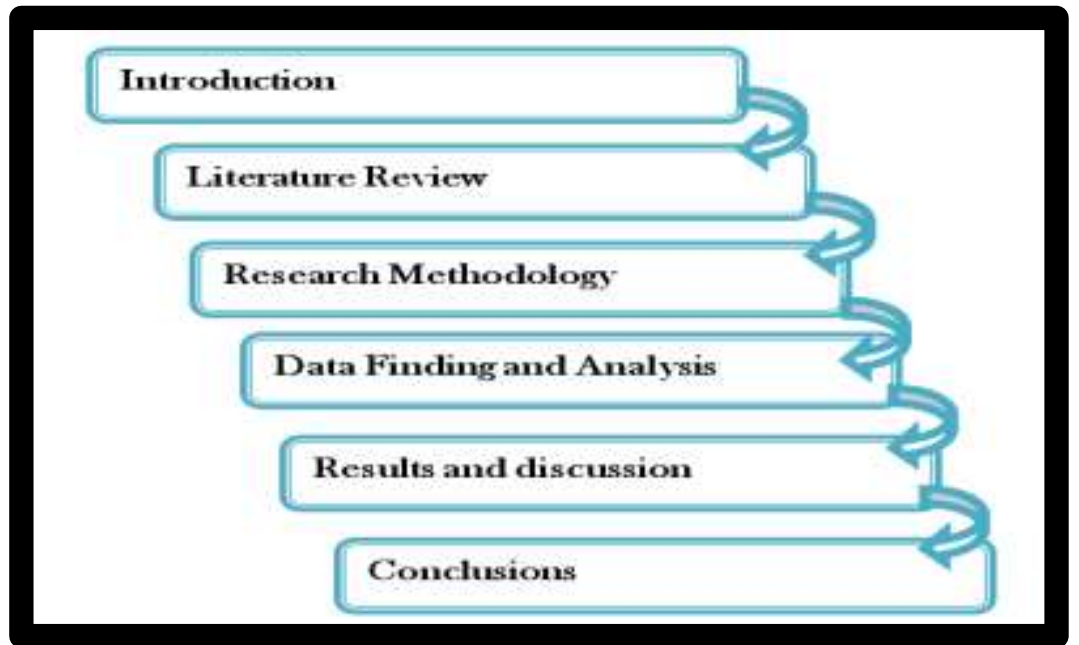

Figure 1: Structure of the Study

\section{LITERATURE REVIEW}

\subsection{Conceptual framework}

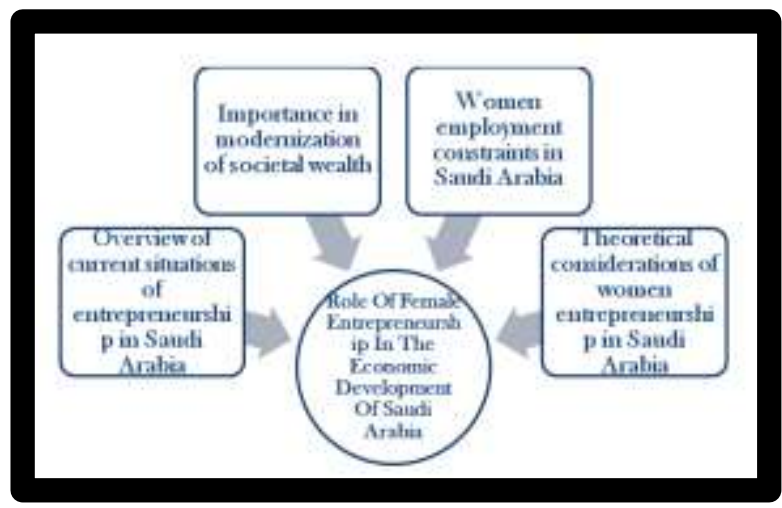

Figure 2: Conceptual Framework

\subsection{Overview of current situations of entrepreneurship in Saudi Arabia}

Entrepreneurship is generally termed to be any impact that is placed over a nation or a place through the application of strategic measures in maintaining social wellbeing through monetary transactions. The current state of Saudi Arabia in entrepreneurship context relies upon the strength of men in imposing business strategies and dealing with import-export of production services from their Nation to others (Williams et al., 2019). According to the economic reports it has been observed that Saudi Arabia is one of the leading and rapid growing Nations in entrepreneurship and development. This is because the nation has possession to a huge number of oil refineries that enables them to gather Economic Strength in context to their dependence over oil business. However, Samargandi et al., (2019) stated that recent traits say that Saudi Arabia tries to diversify their economic growth stability in an independent way that is through other business platforms rather than oil Exports. For this purpose, several rules and regulations that are related to the restriction against women employment need to be altered and new rules are to be established that would encourage the women to attend entrepreneurship opportunities. Moreover, Alfarran et al., (2018) opined that this constraint may require huge support by the government officials of Saudi Arabia as well as female residence who are willing to take upon the responsibility of being an entrepreneur. Through this regulation, it is expected that the country would easily achieve a sustainable position in the global market of entrepreneurship. 


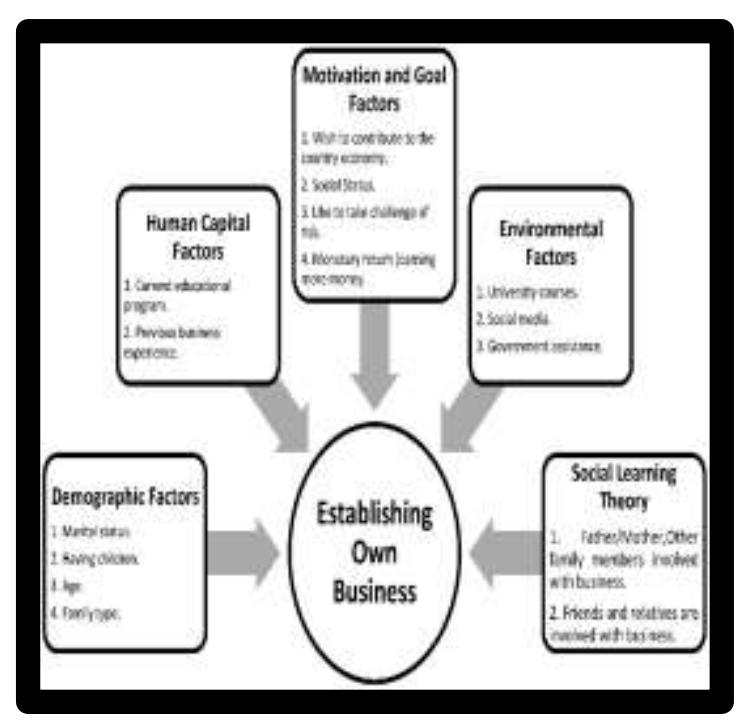

Figure 3: Factors affecting self-entrepreneurship (Source: Influenced by Ye and Gawronski, 2016)

\subsection{Importance in the modernization of societal wealth}

Every developing country in this modern era thrives to produce huge skilled employee force to gain financial capital for the betterment of the Global and the local economy. As per the views by Syed et al., (2018), this attempt of the Saudi Arabian government has led them to establish opportunities for women to attain employment and would grow their initiatives towards entrepreneurship. For this purpose, the Saudi government has established various laws and regulations that provided opportunities to Young women in attaining education and thereby achieved employment. This is because women staying home main pursue and preserve the cultural and societal regulations but with simultaneous effort in developing own self to educational and Employment the women can provide the nation with financial capital growth.

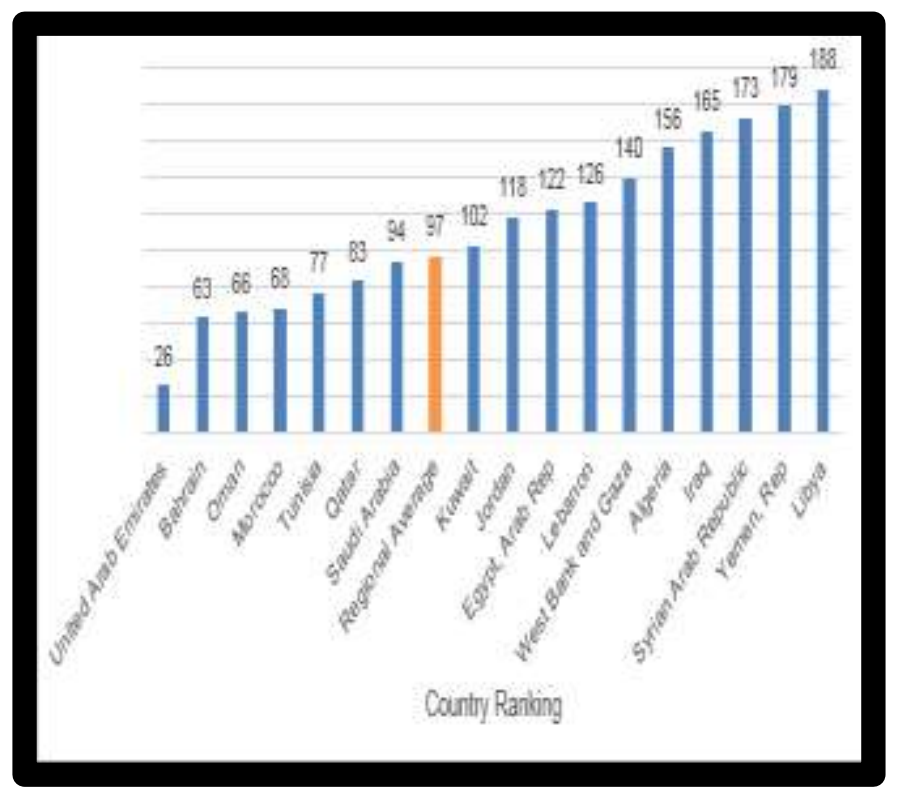

Figure 4: Women employment rankings

(Source: Influenced by worldbank.org, 2020)

According to the reports that were published by the Saudi Arabian Ministry of Higher Education it has been observed that women make up almost $65 \%$ of the total enrolment of university level education which deliberately increases time after time (worldbank.org, 2020). However, complying this measure with that of the workforce potential there has been found a leg of $15 \%$ for Saudi Arabian women. In order to mitigate this, issue the Saudi Arabian government has taken up counter act through training and development of women to pursue more career choices to build up their own business. 


\subsection{Women employment constraints in Saudi Arabia}

Employment of women in Saudi Arabia has always been an issue due to the various restricted policies that are based upon women by the government authority of the nation. As per the views by Young (2017), it is believed that the restrictions upon women are not due to the empowerment of men but due to the cultural welfare that they follow since long years back. These religious drawbacks against women are not only imposed regarding Entrepreneurship and job opportunities but are also addressed to educational rights, government policies social culture and economy. Moreover, Bhutto and Rind (2019) stated that according to Islamic laws of culture and religion women poised of pursuits upon having pursuance of education and Employment with their society. These gender based restrictions imposed upon women from generations which in this modern era means to be rectified for the betterment of the Nations regarding business and economic growth.

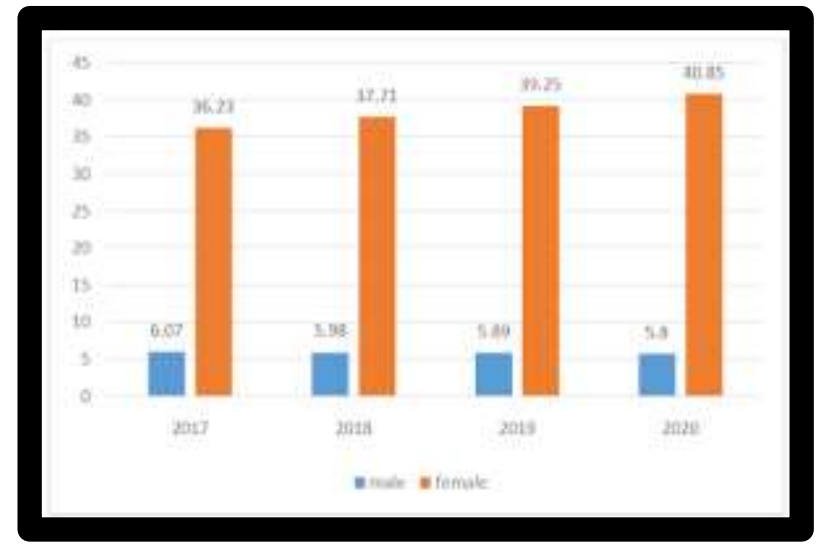

Figure 5: Employment status of Saudi Arabia (Source: Influenced by worldbank.org, 2020)

Taking into account the lifestyle of the Saudi Arabian communities men is raised in such a way that they possess strength, stay tough and become independent. On the other hand, Hussin(2019) stated that women are raised to look after the family and are restricted from availing any fundamental rights that are provided to men. This has been identified to be one of the major reasons why men are overpowering women in the Saudi Arabian region. Recently the initiative of the government as well as the development sectors of the nation has introduced opportunities for women to avail entrepreneurship and lead the nation to attain Economic Strength. However, Alotaibi et al., (2017) argued that even after having such opportunities of a leading women being an entrepreneur there has been several restrictions regarding the business executive pattern of women. For instance, the workplace environment of the organisation that is executed by a woman needs to be comprised of only women staff and the organisation needs to be placed in a separate section from that of the men's division. This in turn not only limits the ability of a woman to earn their own source of income for themselves but also imposes their family from realising their full potential towards contributing for socio economic development.

\subsection{Theoretical considerations of women entrepreneurship in Saudi Arabia}

Various theoretical aspects of entrepreneurship have been defined by several researchers all over the world that addresses to women entrepreneurship and development. This study would deliver these theoretical aspects in terms of the current condition of the Saudi Arabian socio economic reforms and women entrepreneurship opportunities. The effectiveness of applying these theoretical perspectives would provide an overview of the future of women regarding their self-development in leading an organisation in the same Nation without affecting religious cultures.

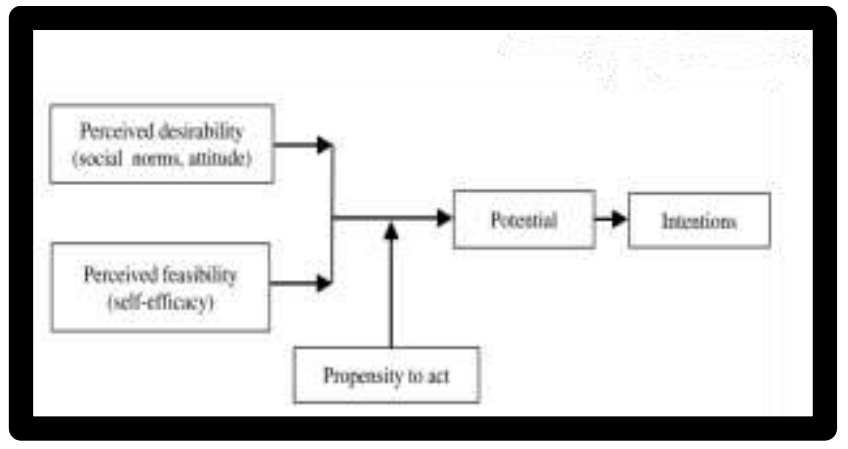

Figure 6: Krueger and Brazeal's model of Entrepreneurship potential (Source: Influenced by Kruegar and Brazeal, 2018) 
The application of Krueger and Brazeal's model of entrepreneurship potential has been applied in this study with respect to the Saudi Arabian context of women empowerment. As opined by Kruegar(2020), the theory derives three Major aspects of women potential realisation through perceived desirability, perceived feasibility and prosperity to act. The above depicted arrangement of the constraints of the Krueger and Brazeal's model of entrepreneurship is a generalized simplified view of the perceivable factors that influence women to attain entrepreneurship potential. Each event and its associated intention are represented to a data flow through which the perception of an individual desires potential to act and thereby reach the goals and objectives as termed as intentions. However, Syed et al., (2018) stated that the restrictive family and cultural drawbacks that Saudi women faces impacts their decision making processes which needs to be deeply intervene so as to provide them with the desired opportunity. According to Krueger and Brazeal(2018), various researchers found that the model of entrepreneurship potential is capable of describing the constraints on the basis of Saudi women's choices of career development. This indicates that individuals with higher perceived Desire and their feasibilities are tending to exhibit entrepreneurship potential. On the other hand, the extensive restrictions in the deeply rooted culture of Saudi Arabia have prevented women to develop their own business which impacts their self-efficacy.

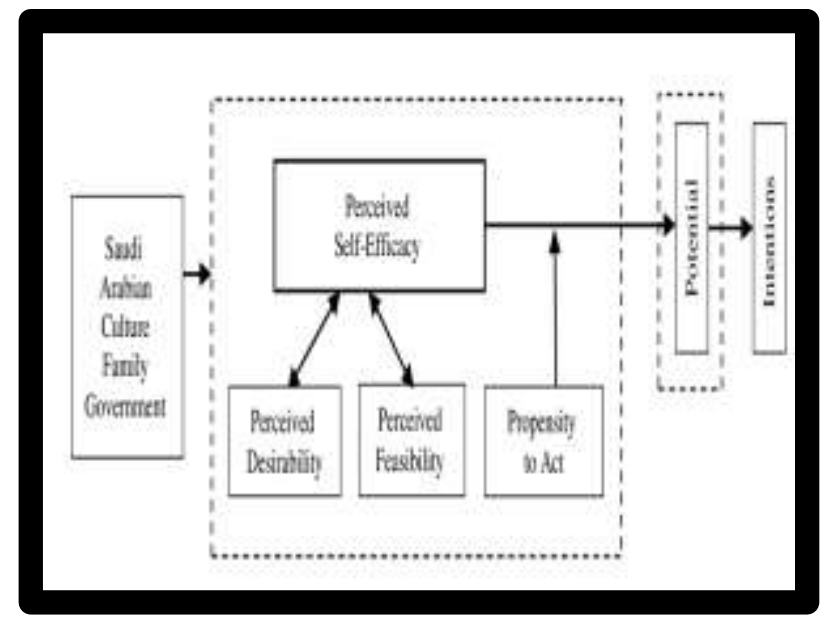

Figure 7: Krueger and Brazeal's model in women entrepreneurship in Saudi Arabia (Source: Influenced by Kruegarand Brazeal, 2018)

The Krueger and Brazeal's model of entrepreneurship potential has been rearranged with a near alignment with the women employment criteria in Saudi Arabia through cultural family and governmental policies. According to Mukesh et al., (2018), this modified perception it is expected that the qualities which the women of Saudi Arabia lack is defined through cognitive physical and social experiences in executing a business and make their own decisions. This is because Saudi women are limited to exposure of opportunities that may lead them to achieve a position of a business woman. One of the important concepts of the entrepreneurship model provides a disposition of an individual to make her own decisions.

\subsection{Literature gap}

The study fails to identify the effectiveness of application of women entrepreneurship opportunities in the socio economic environment of Saudi Arabia. The research needs to be further developed in context to women empowerment in the Islamic culture so as to enhance the ability of a woman to generate an entrepreneurship development in Saudi Arabia. Moreover, the study would require evidential information about the current applications and norms that are poised upon women by the Saudi Arabian government in pursuing employment. 


\section{RESEARCH METHODOLOGY}

\subsection{Research Onion}

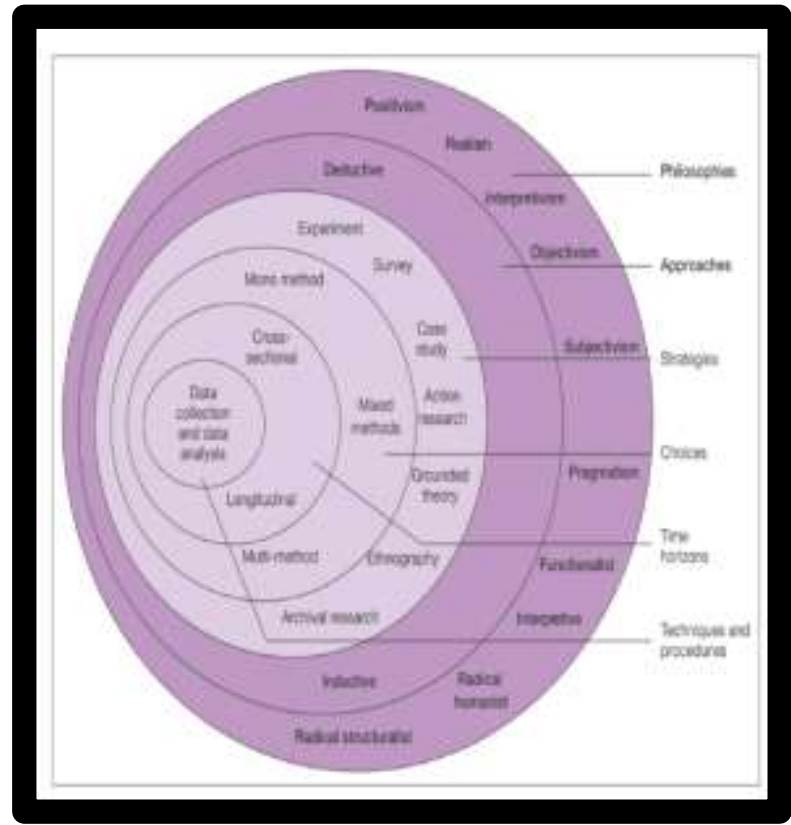

Figure 8: Research Onion

(Source: As Influenced by Saunders et al., 2015)

\subsection{Research Philosophy}

Research philosophy is the belief about the way by which the information and data has been collected and analysed to understanding the aspects for the research topic. As opined by Dougherty et al., (2019), research philosophy is of different types that includes positivism, realism, pragmatism and interpretive. In this study, the research implements the positivism approaches in order to collect the necessary requirement to investigate the roles and responsibility of female entrepreneurship in the development of economic condition of Saudi Arabia. The main reason for selecting the positivism philosophy is that with the help of that research the researcher can able to collect the ancient and historical data to analyse the impact.

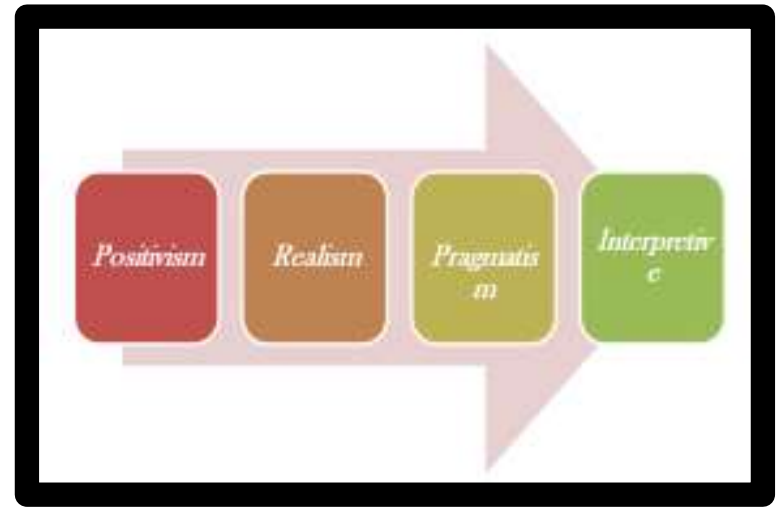

Figure 9: Research Philosophy

(Source: As Influenced by Dougherty et al., 2019)

\subsection{Research Design}

The research design mainly refers to the complete strategy that has been selected to integrate the different types of components of the study in logical and coherent manner. It has been observed that with the help of research design the researcher gets the overview for the completion of research. According to Creswell and Creswell (2017), research designs are of different types that includes descriptive, correlation, experimental and casual-comparative. In this study, the researcher implements the observation and experimental design in order to collect the respective responses for the research subject areas. In addition to this, with the help of observation and experimental data the researcher can able to analyse the role of female entrepreneur in the modern days as compared to the ancient time. 


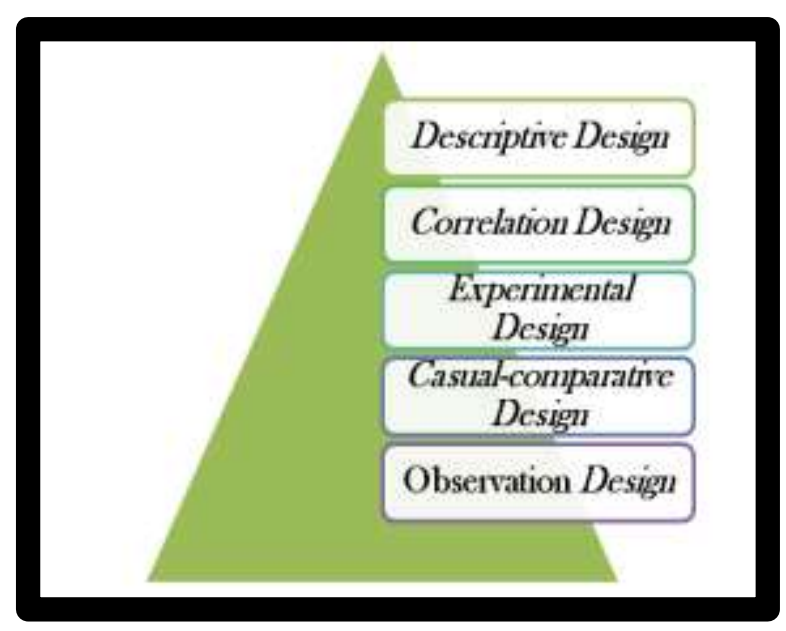

Figure 10: Research Design

(Source: As Influenced by Creswell and Creswell, 2017)

\subsection{Research Approaches}

Research approaches are the board plan and procedure that helps the research scholar to gain an abrupt idea about the execution of the research. As per the learning of Fischer et al., (2017), there are three types of research approaches that include deductive, inductive and adductive research approaches. In this study deductive research approach has been selected in order to gain the in-depth understanding about the research topic. On the other hand, Gaus (2017) have mentioned that deductive research approach mainly explores the different types of theory and phenomenon to formulate the research question and hypothesis for the testing of the research process. Therefore, with the help of that approach the researcher can able to highlight the factors that enhance the role of female entrepreneurship in the development of economic condition in Saudi Arabia.

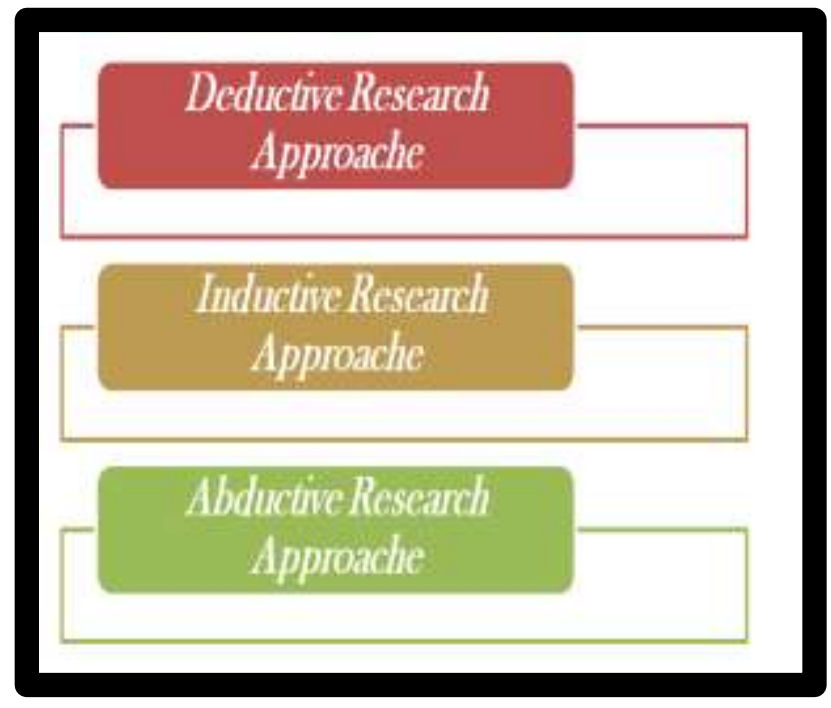

Figure 11: Research Approaches

(Source: As Influenced by Fischer et al., 2017)

\subsection{Data collection Methods}

The data collection is one of the important parts of the research that helps the researcher to collect the necessary data and information for the research. As opined by Paradis et al., (2016), data collection is the method of gathering and measuring the data and information on variable of interest and it also enable an individual to answer the stated research question and also evaluate its respective outcomes. The data collections are of three types that includes qualitative, quantitative and mixed data collection. In this research, qualitative data collection has been undertaken and the research has been formulated with the help of thematic analysis. On the other hand, Ostrow et al., (2017) have mentioned that in thematic data collection the research scholar collect the historical data and observation to analysis the results and outcome for the research. Moreover, in these research five different pearly reviewed articles has been selected from Google scholar in order to collect the historical and experimental data for the research. 


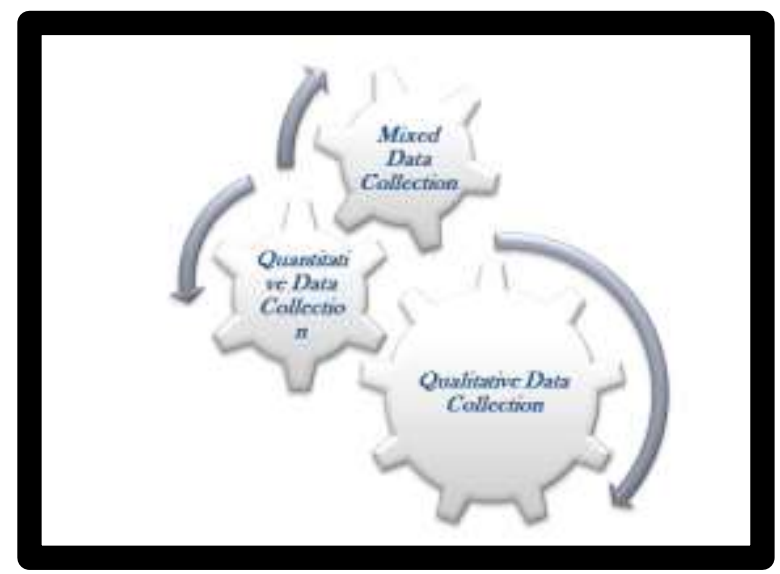

Figure 12: Data Collection

(Source: As Influenced by Ostrow et al., 2017)

\subsection{Data Analysis}

The data analysis is one of the important and crucial parts of the research that helps the researcher to analysis the result and the observation that has been collected from data analysis. Additionally, Schabenberger and Gotway (2017) have mentioned that data analysis is of different types that includes statistical, thematic and observation data analysis. In this research thematic data analysis has been selected in order to analysis the result of the collected information and data.

\subsection{Limitation of research}

The research limitation is the physical boundaries of the research that enhance the researcher to implement the future work on the research. In this research only qualitative approach of data collection has been selected and in future the research scholar also needs to perform interview and open ended question in order to provide the strong in-depth analysis about the research. It can be stated that with the help of open ended questions the researcher can able to get the overview of the individual's issues for analysis the results of the research.

\subsection{Ethical Consideration}

This research has been performed with the help of qualitative data analysis and collection. In this research the research scholar strictly implements the data protection act and after getting the permission they are extracted the respective article from Google Scholar. In addition to this, before the starting of the research the scholar duly signed the research data storage norms and conditions and provides the declaration that the data that has been collected is only use in the research purpose.

\section{DATA FINDING AND ANALYSIS}

\subsection{Secondary Data Finding}

\subsubsection{Thematic Analysis}

\begin{tabular}{|c|c|c|c|}
\hline Year & Author & Topic & Theme \\
\hline 2018 & $\begin{array}{l}\text { "Chandran, D. And Aleidi, } \\
\text { A" }\end{array}$ & $\begin{array}{l}\text { "Analyzing the Influence of Gender } \\
\text { Stereotypes and Social Norms on Female IT } \\
\text { Entrepreneurial Intention in Saudi Arabia" }\end{array}$ & $\begin{array}{lcr}\text { Aspect } & \text { of } & \text { female } \\
\text { entrepreneurship in Saudi Arabia }\end{array}$ \\
\hline 2019 & 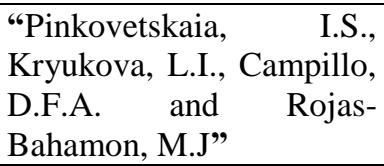 & $\begin{array}{l}\text { "Female entrepreneurship: Types of } \\
\text { economic activity" }\end{array}$ & $\begin{array}{l}\text { Activities of } \\
\text { entrepreneurship female } \\
\begin{array}{l}\text { development of } \\
\text { conditions }\end{array}\end{array}$ \\
\hline 2019 & "Ennis, C.A" & $\begin{array}{l}\text { "The gendered complexities of promoting } \\
\text { female entrepreneurship in the Gulf" }\end{array}$ & $\begin{array}{l}\text { Impact of gender inequality for } \\
\text { the development of economic } \\
\text { conditions }\end{array}$ \\
\hline 2016 & $\begin{array}{l}\text { "Berger, E.S. and } \\
\text { Kuckertz" }\end{array}$ & $\begin{array}{l}\text { "Female entrepreneurship in startup } \\
\text { ecosystems worldwide" }\end{array}$ & $\begin{array}{l}\text { Female entrepreneurship } \\
\text { activities for startup ecosystem }\end{array}$ \\
\hline 2016 & $\begin{array}{l}\text { "Welsh, D.H., Kaciak, E. } \\
\text { And Thongpapanl, N" }\end{array}$ & $\begin{array}{l}\text { "Influence of stages of economic } \\
\text { development on women entrepreneurs' start- } \\
\text { ups" }\end{array}$ & $\begin{array}{l}\text { Stages of influences of economic } \\
\text { development on women } \\
\text { entrepreneurship }\end{array}$ \\
\hline
\end{tabular}

Table 1: Thematic Analysis 


\section{Theme 1: Aspect of female entrepreneurship in Saudi Arabia}

In the recent days, the technological entrepreneurship has one of the most important driving factors for the growth of economic condition in the nation. As per the view point of Chandran and Aleidi (2019), the phenomenon of female entrepreneurship activities in society has been characterised with the help of high level of stereotypical expectation of gender towards the business of technologies and also in the gender role in Saudi community. It can be stated that it is quite important to enhance the women participations in the venturing of business for enhancing the level of innovation in the business. On the other hand, Henry et al., (2017) the development of economic condition is based in the innovation in the business and also needs to undertake the factors and decision making process that might affect the women engagement in the business. In the recent days, women entrepreneurship has recently become one of the emerging topics in the market of Saudi Arabia.

It has been observed that based on the traditional norms and rules in Saudi Arabia or in Islamic region women have its restriction to join in the economic field for a long term. According to Aleidi and Chandran (2017), from the early stage of $21^{\text {st }}$ century women entrepreneurship has driven largely by changing the direction of the Saudi Arabia government in order to support the women empowerment and gender equality. Taking into consideration, the Ninth Development Plan of Kingdom (2010-2014) embedded a new phase in the development by providing the greater opportunities for the employment for women and encouraging the more numbers of women to join the economic field. Additionally, Vision 2030 is the new phase of Plan that has been imposed by Saudi Arabia government is related to the development by supporting and promoting the SME entrepreneurship in order to creates a suitable job opportunity for Saudi citizens.

\section{Theme 2: Activities of female entrepreneurship in the development of economic conditions}

In the earlier days, female entrepreneurship activities have been limited to its certain numbers of sectors that includes agriculture, mining, health care and education. In the earlier days, female of Saudi Arabia is not allowed to join in the economic development for the nation and that is because of the Islamic rules and the traditional activities. According to recent statistical data, the female activities in entrepreneurship are based on the TEA ranking for the entrepreneurship activities.

\begin{tabular}{|c|c|}
\hline Country & TEA \\
\hline Norway & 3.8 \\
\hline South Africa & 5.9 \\
\hline Mexico & 10.0 \\
\hline Uruguay & 9.9 \\
\hline Israel & 9.4 \\
\hline Iran & 8.9 \\
\hline Saudi Arabia & 5.9 \\
\hline Chile & 19.8 \\
\hline Thailand & 15.7 \\
\hline Indonesia & 15.6 \\
\hline Russia & 5.7 \\
\hline
\end{tabular}

Table 2: TEA Comparison

(Source: As Influenced by Pinkovetskaia et al., 2019)

In the gulf countries, women have been restricted to join their potential hand in the economic development. Taking into consideration of Islamic tradition, they believe that women are not physically strong to perform any kind of hard activities and also they are not able to handle the tough situation. As opined by Pinkovetskaia et al., (2019), in the ancient time most of the women are only perform their activities in the agricultural sectors and engage themselves for the family welfare. As per the statistical data of Central Department of Statistics and Information in the year 2013, Saudi women above 15 years are unemployed as compared to $6.1 \%$ men in the kingdom of Saudi Arabia. From the above table and data, it can be stated that in the Gulf countries there are high rate of unemployment among the women as compared to men because of the traditional restriction. In fact, from the year 2001-2010 approximately 1.5 million gulf countries women in GCC joined as a labour force (Pinkovetskaia et al., 2019). Therefore, it can be stated that female entrepreneurship is one of the emerging aspects that helps the nation in the development of its economic condition (Dean et al., 2019). The GCC countries women also have the potentiality to handle the high level of stress in their workplace and that is one of the positive reasons for the development of economic condition in the market of Saudi Arabia.

\section{Theme 3: Impact of gender inequality for the development of economic conditions}

Gender inequality is one of the emerging reasons that play an essential role in the degradation of the economic condition for the nation. In the $21^{\text {st }}$ century, there are no such gender inequality still arise in between men and women in the world. 
For example, if a man can able to develop a software by considering the tough situation then in the same way a woman is also have the potential to develop that one. Taking into account of the GCC countries, there are still the misunderstanding occurs among the men and women. According to the Islamic tradition especially in the Saudi Arabia countries women are not allowed to go out and contribute their hand in the economic development. As opined by Ennis (2019), the main reason for gender inequality has been emerges because of the education gaps in the market. it is completely wrong faith that only men have the capabilities for the contribution in the global economic market. on the other hand, Chang et al., (2019) have mentioned that large numbers of gender pay gaps mainly leads to the sustainable losses of output due to the impact that they have on fertility and female participations. It has been observed that around $27 \%$ of the losses faced by the Middle East/North Africa region because of the restriction for female entrepreneurship.

\section{Theme 4: Female entrepreneurship activities for start-up ecosystem}

The start-up ecosystems have positive impacts for the development of new business in the entire world. In the modern world, innovation comes from the both men and women in the business and entrepreneurial activities mainly reflect on the high level of contribution ion the ecosystem. It has been observed that female entrepreneurship activities for startup are about to 7\% in the market of Saudi Arabia and it is still increasing. As opined by Berger and Kuckertz (2016), the characteristics of ecosystem mainly enhanced with the help of high proportions of female founders in the respective ecosystem. Taking into consideration of Saudi Arabia, there are still the traditional approach of Islamic has been implemented and that is the reason that the women are not able to perform their best for the nation. In the mid of $21^{\text {st }}$ century the activities of female entrepreneurship have been raise but they are only restricted to perform their activities in SME enterprises.

In the present days, the economic condition of Saudi Arabia is quite stable and the main reason is for its enhancement in the oil industries. On the other hand, Hechavarría and Ingram (2019) have mentioned that the culture and women in Saudi Arabia in the market of Saudi Arabia women line in a male dominated and men exert strict codes and unwritten social norms on the women of Arabia. It has been observed that the gender segregation mainly leads for the degradation of the economic condition and leads to the public space where they can able to practices the range of activities that they have such as in school, government offices and in others.

\section{Theme 5: Stages of influences of economic development on women entrepreneurship}

The women activities and entrepreneurship mainly add to the economic wellbeing of countries. According to Welsh et al., (2016), the different stages of influence of the economic development on women entrepreneurship include family support, personal problems and family moral supports. It can be stated that personal problem is related to the entrepreneur that mainly perceived during the start-up phases of its business. On the other hand, Ngoasong and Kimbu (2019) have mentioned that personal problem also includes emotional stress, loneliness, family stress, time management and poor or low support. Taking into consideration of family moral support, family moral support is intangible support that includes the family social capital and the different types of capitals that has been inheriting in the family relationship. In Saudi Arabia, these issues have been emerged in front of female entrepreneur. The other essential influence that has been trending in the Islamic region is family instrumental support that mainly takes the different forms of comments from the family member's ideas and advices. As opined by Welsh et al., (2016), family instrumental support also includes the assistance with the household responsibilities and it also may take in the forms of loans. Therefore, it can be stated that by enhancing the different strategies the female entrepreneurship ideas can be enhanced and it also helps the nation to develop their potential economic aspects from the market.

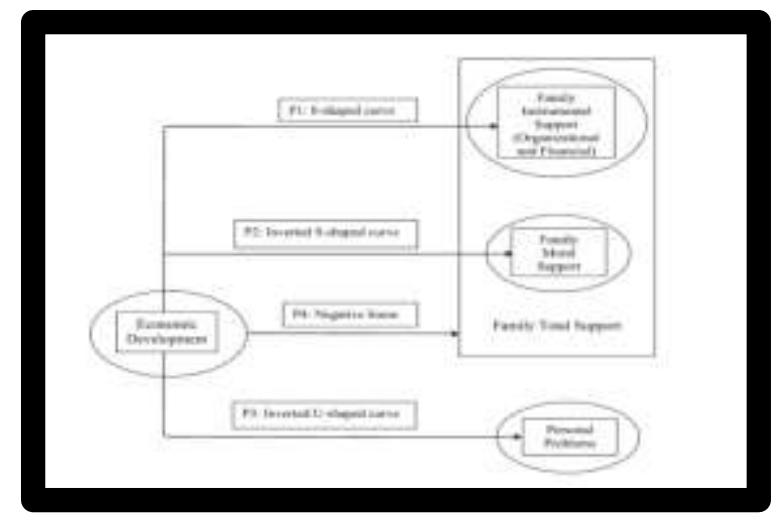

Figure 13: Stages of influences of economic development on women entrepreneurship (Source: As Influenced by Welsh et al., 2016) 


\section{RESULTS AND DISCUSSION}

The establishment of a business in the regional environment of Saudi Arabia has been observed to be a challenge in aspect for women. This is because women in Saudi Arabia and its regional sections are subjected to face restrictions regarding the opportunities of employment and educations. As per the views by Varshney (2019), these restrictions are subjected to the cultural and religious specifications that Islamic men and women follow since generations. The significance of having these restrictions addresses to the fact that being physically weak women would not be able to handle pressurized situations than that of men. Hence, expanding monetary Investments in favour of women would ultimately result in loss of economy which would have been profitable for or to be established. However, Varshney(2018) opined that these backdated norms are recently overcome by the Saudi Arabian government by assessing various resultant prepositions that are established by many organisations all over the world. This indicated that the participation of women in business and entrepreneurship has led many organisations to achieve their goals and objectives in an efficient way as a then participating with only men.

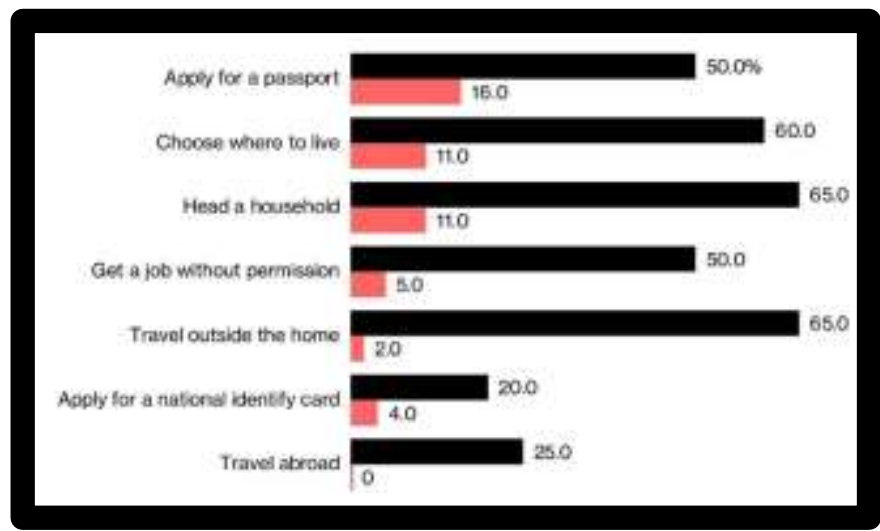

Figure 14: Women rights in Saudi Arabia

(Source: Influenced by statista.com, 2020)

Gender diversity in workplace has been made a necessary Criterion for the Global organisations to operate their business with the higher level of cultural and equality aspects. Moreover, Zhong and Guo(2017) stated that the educational opportunities that are provided to women throughout the world has let them reach higher sections of economic growth for their own Nations. Similarly, the Saudi Arabian government upon having name as the dominant gender among their cultural and economic aspects provided damp to include men in business participations rather than women. Recently the initiatives of the government has provided women to attain opportunities regarding educational rights in universities such that they would be able to employees themselves in their own business.

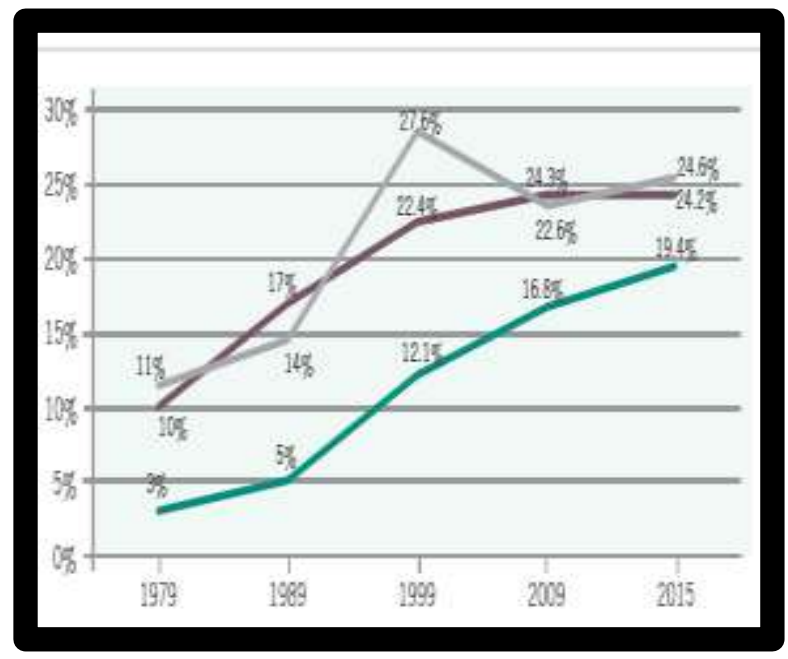

Figure 15: Increase in women employment rates in Saudi Arabia and the global regions (Source: stastista.com, 2020)

Based on the various records that have been observed from all around the globe it could be stated that the unemployment rate of women in the Islamic ruled regions are much higher than that of other regions the main reason behind this occurrence have been addressed to the religious and cultural aspects of the Islamic personnel specially those residing in the Saudi 
Arabian region. The above graphic representation and statistical analysis that has been conducted provide a comparative study between the unemployment rate of women in the Saudi Arabian region to that of the world. It has been observed that $3 \%$ women employment were allowed in the late nineties whereas in the past few years it has been increased to $19.4 \%$ of employment rate for women (statista.com, 2020). Similarly comparing this statistic to that of the world's record 24.6 percent has been increased which contributed towards equality factor regarding men and women employment diversification.

Undertaking this responsibility by the government has facilitated the women to grab higher level of rights compared to that of which they used to get. As exclaimed by Wahid (2019), even after having such rights being poised upon them these are limited to certain extent so as to maintain their cultural as well as economic growth benefits. In other words, the women of Saudi Arabia would be able to become an interpreter of an owner of business organisation that would only comprise of women as the employees and in a different section of the market. As stated by Yang et al., (2019), this indicates that opportunities will be provided to women but gender diverse atmosphere would not be entertained in organisation that comprises of men as well as women. It is expected that in future the government would take necessary actions and steps to mitigate these restrictions and enhance equality factor among men and women in pursuing business and employment.

Taking into account the benefit of having women as an entrepreneur in the regional business environment of Saudi Arabia it is expected that the Nation would gain a higher amount of economic growth in terms of monetary and financial transactions. This is because the empowerment of women would not only open up opportunities to achieve equality but would also enhance the economy of the nation to attain business benefits in terms of foreign exchange (Chant, 2016). In other words, the dependency of Saudi Arabia in their all refinery business has let them to achieve one of the richest economic in the world. However, Florian et al., (2017) argued that with the improvement and advancement of Technologies and other business sectors the business organisations of Saudi Arabia would also be required to establish their strength and growth apart from that of oil business. Through this measure the country would not only be able to improve their financial strengths but would also be able to achieve a sustainable position in the Global market regarding other business products and services. Aligning this factor with that of women employment the increase in business sectors would require organisations to hire employees who would be specialised in certain field of work and thereby provide opportunities to women in attaining those positions. Similarly, a woman entrepreneur would be able to govern self-owning organisation that may deal with various products and services to stabilize many sections of the country to grow and develop regarding financial benefits.

\section{CONCLUSION AND RECOMMENDATION}

\subsection{Conclusion}

From the above discussion, it can be concluded that in the modern world, female entrepreneur feels more in control and happier according to the situation than if they worked as an employees. Female entrepreneurship has been considered as the one of the important source for the economic growth and helps the nation by creating the new job opportunities for themselves and others in the market. In addition to this, the female entrepreneurship development mainly creates organisation that offers the employment to million numbers of people. In the market of Saudi Arabia the role of female entrepreneurship is not able to contribute their best for the nation economic development. The main reason for that is the traditional rules and regulation of Islamic religion in those countries. According to the Islamic regions women are completely depended on the male and they are not allowed to invest on the economy. In most of the Islamic countries they have the faith that women are not able to handle tough situation and implement decision. This study also sheds light on the current overview of the situation of entrepreneurship in the market of Saudi Arabia. The current scenario of Saudi Arabia mainly emerges with the help of oil industries. In fact, the government of Saudi Arabia launches Vision 2030 in order to promote the female entrepreneurship and creating new job opportunities in the market.

\subsection{Linking with Objectives}

\section{Objective 1: To determine the importance of entrepreneurship activities in the development of economic condition for} the nation

This objective successfully meets in Introduction and literature review section. This objective is met by reflecting the importance and the role of female entrepreneurship in the development of economic condition for Saudi Arabia.

\section{Objective 2: To evaluate the impact of female entrepreneurship in development of economic condition of Saudi Arabia}

This objective is met in the section literature review with the help of different factors that provide the overview of the female entrepreneurship in the market of Saudi Arabia. In addition to this, the impact of female entrepreneurship is quite negative in the latent time and it is improving in the recent time and that is the reason that they are getting the opportunities. 
Objective 3: To investigate the role of female entrepreneurship in the development of economic condition of Saudi Arabia

This objective is met in literature review and in data finding sections. The role of female entrepreneurship has been extended from the agriculture and the other sectors in the market. It can be stated that in both the section different types of role and responsibilities has been highlighted in order to complete the respective objective for the research.

\section{Objective 4: To assess the issues that has been faced by the female person in female entrepreneurship for the development of economic condition in the nation}

This objective is successfully met in data finding and discussion sections. In both the section different types of issues has been highlighted that has been faced by the female in Saudi Arabia. The issues has been emerges because of the tradition rules and assumption of Islamic religious.

\section{Objective 5: To provide the necessary strategies in order to resolve the issues of female entrepreneurship for the development}

This objective is met in Discussion and Recommendation sections. The different types of strategies have been provided in order to resolve the issues of female entrepreneurship in the market of Saudi Arabia.

\subsection{Future Scope and Limitation}

The future scope of the research is that the researcher needs to expand the ideas of research and collecting the necessary information with the help of open ended questions. In future studies the research scholar also needs to perform interview and survey with the different female entrepreneur in order to get an abrupt idea about the issues that has been faced during their working activities in the Islamic regions. The research is limited to secondary data collection that is thematic analysis. The researcher is not able to collect the personal perception about the issues and the role of female entrepreneurship for the development of economic condition in Saudi Arabia.

\subsection{Recommendation}

It can be recommended that the government of Saudi Arabia and their society needs to implement the following

- It is the responsibility of government to promote the positive aspects of female entrepreneurship and their role in the society in order to create ample numbers of job opportunities.

- It can also be stated that the society also needs to accept the capabilities of female and motivate them for betterment of the nation economic conditions in the market.

- The change is also required based on the Islamic tradition because in the modern days everyone has the responsibilities to enhance and improve the condition of the nation in terms of economic development.

- It can also be recommended that the government of Saudi Arabia needs to promote the social awareness in enhancing the women empowerment and equality within the nation. It can also be stated that the society and government are also responsible to reduce the generation gap and minimise the education gap among the citizens of Saudi Arabia.

- It can also be suggested that the government of Saudi Arabia needs to regular and implement the special laws and regulation in order to maintain the level of protection for women in the market.

\section{REFERENCES}

- Aleidi, A.I. and Chandran, D., 2017, July. Does Institutional Environment Promote Women's IT Entrepreneurial Intention in Saudi Arabia? Technological and Institutional Perspectives. In The Pacific Asia Conference on Information Systems.

- Alfarran, A., Pyke, J. and Stanton, P., 2018. Institutional barriers to women's employment in Saudi Arabia. Equality, Diversity and Inclusion: An International Journal.

- Alotaibi, F., Cutting, R. and Morgan, J., 2017. A critical analysis of the literature in women's leadership in Saudi Arabia. International Journal of Business Administration and Management Research, 3(1).

- Berger, E.S. and Kuckertz, A., 2016. Female entrepreneurship in startup ecosystems worldwide. Journal of Business Research, 69(11), pp.5163-5168.

- Bhutto, S. and Rind, B.A., 2019. ENGLISH-THE PREVALENCE OF SEXUAL ABUSE IN WOMEN (TYPES, CAUSES, EFFECTS) AND ITS REMEDIES IN ISLAM. The Scholar-Islamic Academic Research Journal, 5(2), pp.128-138.

- Chandran, D. and Aleidi, A., 2018. Analyzing the Influence of Gender Stereotypes and Social Norms on Female IT Entrepreneurial Intention in Saudi Arabia. Hawaii International Conferenceon System Sciences. 
- Chang, Q., Yip, P.S. and Chen, Y.Y., 2019. Gender inequality and suicide gender ratios in the world. Journal of affective disorders, 243, pp.297-304.

- Chant, S., 2016. Women, girls and world poverty: empowerment, equality or essentialism?. International Development Planning Review, 38(1), pp.1-24.

- Creswell, J.W. and Creswell, J.D., 2017. Research design: Qualitative, quantitative, and mixed methods approaches. Sage publications.

- Dean, H., Larsen, G., Ford, J. and Akram, M., 2019. Female entrepreneurship and the metanarrative of economic growth: A critical review of underlying assumptions. International Journal of Management Reviews, 2l(1), pp.24-49.

- Dougherty, M.R., Slevc, L.R. and Grand, J.A., 2019. Making research evaluation more transparent: Aligning research philosophy, institutional values, and reporting. Perspectives on Psychological Science, 14(3), pp.361375.

- Ennis, C.A., 2019. The gendered complexities of promoting female entrepreneurship in the Gulf. New Political Economy, 24(3), pp.365-384.

- Fischer, D., Stanszus, L., Geiger, S., Grossman, P. and Schrader, U., 2017. Mindfulness and sustainable consumption: A systematic literature review of research approaches and findings. Journal of Cleaner Production, 162, pp.544-558.

- Florian, A., Montero, C.S. and Mbise, E.R., 2017, September. Mobile technology for women entrepreneurs in Iringa, Tanzania: User requirements and architectural design. In 2017 IEEE AFRICON (pp. 497-503). IEEE.

- Gaus, N., 2017. Selecting research approaches and research designs: A reflective essay. Qualitative Research Journal.

- Hechavarría, D.M. and Ingram, A.E., 2019. Entrepreneurial ecosystem conditions and gendered national-level entrepreneurial activity: a 14-year panel study of GEM. Small Business Economics, 53(2), pp.431-458.

- Henry, C., Nelson, T. and Lewis, K. eds., 2017. The Routledge companion to global female entrepreneurship. Routledge.

- Hussin, S.A.B., 2019. Incorporating Islamic Leadership Key Behaviors in Moderating The Association of Workplace Culture and Discrimination Against Women at Workplace (Doctoral dissertation, UniversitiSains Islam Malaysia).

- Krueger, N., 2020. Entrepreneurial potential and potential entrepreneurs: 25 years on. Journal of the International Council for Small Business, 1(1), pp.52-55.

- Krueger, N.F. and Brazeal, D.V., 2018. PotencialEmpreendedor E Empreendedores EM Potencial (Entrepreneurial Potential and Potential Entrepreneurs). Revista de Empreendedorismo e Gestão de PequenasEmpresas, 7(2), pp.201-226.

- Mukesh, H.V., Rao, A.S. and Rajasekharan Pillai, K., 2018. Entrepreneurial potential and higher education system in India. The Journal of Entrepreneurship, 27(2), pp.258-276.

- Ngoasong, M.Z. and Kimbu, A.N., 2019. Why Hurry? The Slow Process of High Growth in Women-Owned Businesses in a Resource-Scarce Context. Journal of Small Business Management, 57(1), pp.40-58.

- Ostrow, L., Penney, D., Stuart, E. and Leaf, P.J., 2017. Web-based survey data collection with peer support and advocacy organizations: Implications of participatory methods. Progress in Community Health Partnerships: Research, Education, and Action, 11(1), pp.45-52.

- Paradis, E., O'Brien, B., Nimmon, L., Bandiera, G. and Martimianakis, M.A., 2016. Design: selection of data collection methods. Journal of graduate medical education, 8(2), pp.263-264.

- Pinkovetskaia, I.S., Kryukova, L.I., Campillo, D.F.A. and Rojas-Bahamon, M.J., 2019. Female entrepreneurship: Types of economic activity. Journal of History Culture and Art Research, 8(2), pp.253-265.

- Poggesi, S., Mari, M. and De Vita, L., 2016. What's new in female entrepreneurship research? Answers from the literature. International Entrepreneurship and Management Journal, 12(3), pp.735-764.

- Samargandi, N., Al Mamun, M., Sohag, K. and Alandejani, M., 2019. Women at work in Saudi Arabia: Impact of ICT diffusion and financial development. Technology in Society, 59, p.101187.

- Saunders, M.N., Lewis, P., Thornhill, A. and Bristow, A., 2015. Understanding research philosophy and approaches to theory development.

- Schabenberger, O. and Gotway, C.A., 2017. Statistical methods for spatial data analysis. CRC press.

- Statista.com (2020). ECONOMIC GROWTH. Available at: https://www.statista.com/chart/14439/female-drivercar-and-sales-in-saudi-arabia/ [Accessed on 14.6.2020]

- Syed, J., Ali, F. and Hennekam, S., 2018. Gender equality in employment in Saudi Arabia: a relational perspective. Career Development International.

- tradingeconomics.com, (2020) Saudi Arabia - Unemployment, Female Available at: https://tradingeconomics.com/saudi-arabia/unemployment-female-percent-of-female-labor-force-wb data.html\#: : :text=Unemployment $\% 2 \mathrm{C} \% 20$ female $\% 20(\% 25 \% 20 \mathrm{of} \% 20$ female,compiled $\% 20$ from $\% 20$ officially \%20recognized\%20sources. [Accessed on: 27.06.2020] 
- Varshney, D., 2018. Expatriates Go, Let Us Grow: An Analysis of Employment Patterns and Development of a Viable HRD Model of Saudi Arabia. African and Asian Studies, 17(4), pp.340-370.

- Varshney, D., 2019. The Strides of the Saudi Female Workforce: Overcoming Constraints and Contradictions in Transition. Journal of International Women's Studies, 20(2), pp.359-372.

- Wahid, A.S., 2019. The effects and the mechanisms of board gender diversity: Evidence from financial manipulation. Journal of Business Ethics, 159(3), pp.705-725.

- Welsh, D.H., Kaciak, E. and Thongpapanl, N., 2016. Influence of stages of economic development on women entrepreneurs' startups. Journal of Business Research, 69(11), pp.4933-4940.

- Williams, S., Qiu, W., Al-awwad, Z. and Alfayez, A., 2019. Commuting for women in Saudi Arabia: Metro to driving-Options to support women employment. Journal of Transport Geography, 77, pp.126-138.

- Worldbank.org (2020). The State of Women's Rights in the Arab World. Available at: https://www.worldbank.org/en/news/feature/2016/03/07/the-state-of-womens-rights-in-the-arab-world [Accessed on 15.6.2020]

- Yang, Y., Chawla, N.V. and Uzzi, B., 2019. A network's gender composition and communication pattern predict women's leadership success. Proceedings of the National Academy of Sciences, 116(6), pp.2033-2038.

- Ye, Y. and Gawronski, B., 2016. When possessions become part of the self: Ownership and implicit self-object linking. Journal of Experimental Social Psychology, 64, pp.72-87.

- Young, K.E., 2017. More Educated, Less Employed: The Paradox of Women's Employment in the Gulf. Higher Education in the Gulf States: Present \& Future, pp.7-9.

- Zhong, Z. and Guo, F., 2017. Women in Chinese Higher Education: Educational Opportunities and Employability Challenges. In The Changing Role of Women in Higher Education (pp. 53-73). Springer, Cham. 